\title{
Determination of the minimum local anesthetic dose (MLAD) of spinal chloroprocaine for inguinal herniorrhaphy in ambulatory surgery: preliminary results
}

\section{A. Parashchanka, S. Hofman, M. Coppens, P. Wyffels, P. Wouters, S. De Hert}

Department of Anesthesiology and Perioperative Medicine, University Hospital Ghent, Belgium

- Spinal anesthesia for inguinal hernia repair in day surgery necessitates short-acting local anesthetics.

- Chloroprocaine is a well-known local anesthetic with a beneficial pharmacodynamic/-kinetic profile and suitable in ambulatory surgery.

- The primary goal of this study was the determination of the minimum local analgesic dose (MLAD) of 2chloroprocaine with $2.5 \mu \mathrm{g}$ of sufentanil administered intrathecally for inguinal herniorrhaphy in outpatients.

\section{Methods}

- 12 patients recruited

- intrathecal dose by a combined spinal-epidural technique (CSE)

- first spinal dose of 2-chloroprocaine $1 \%$ was $50 \mathrm{mg}$ and the testing interval was $2 \mathrm{mg}$

- analgesic efficacy assessed as successful by getting a sensory block at or above the T6 dermatome bilateral and by a score lower than $30 \mathrm{~mm}$ on a $100 \mathrm{~mm}$ visual analogue pain scale at the beginning of surgery

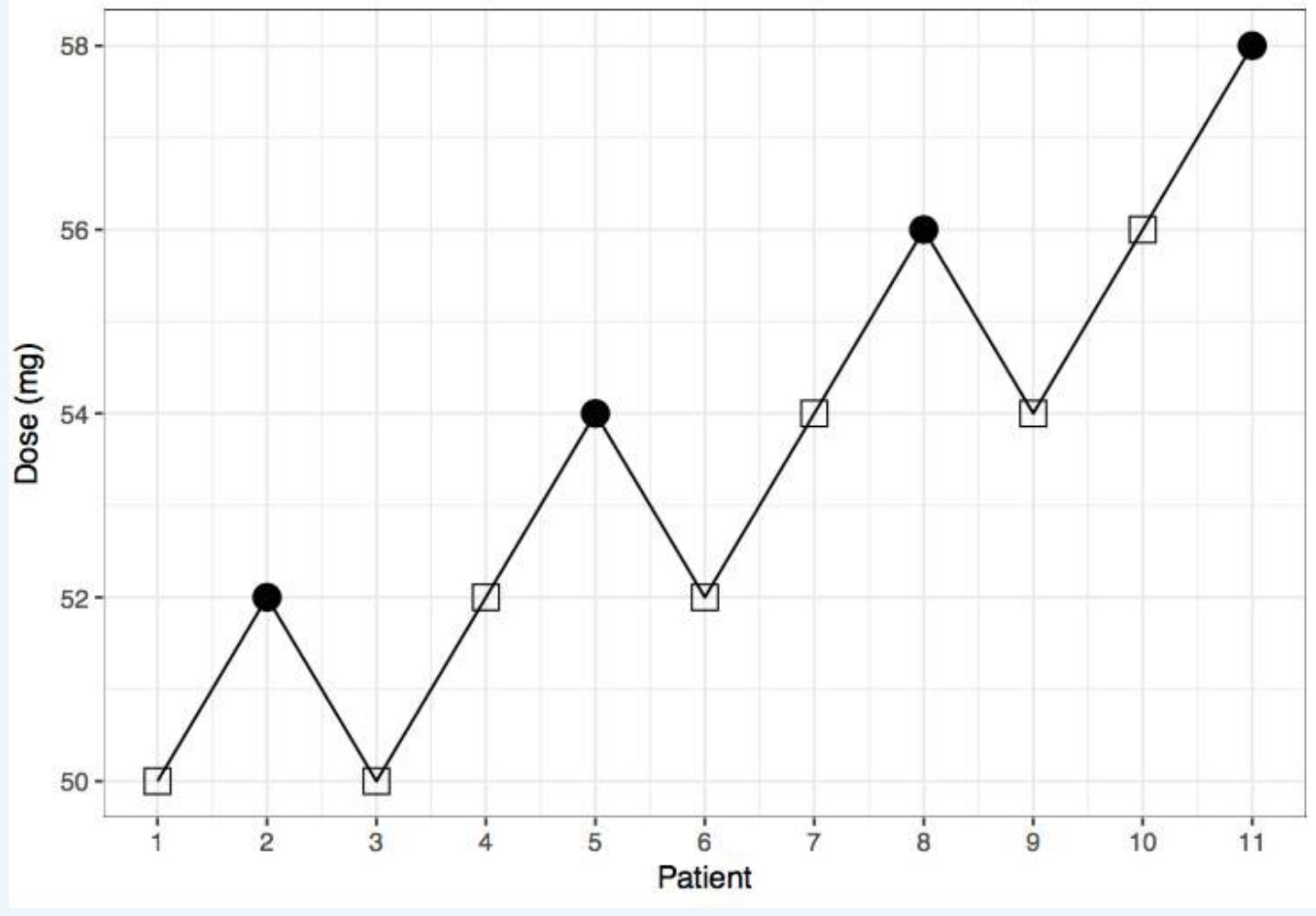

Fig.1.

\section{References}

- Goldblum E., Atchabahian A. Acta Anaesthesiol Scand 2013; 57: 545-552.

- Dan J. Kopacz. Regional Anesthesia and Pain Medicine, 2005, 1.

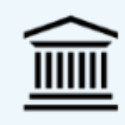

- chloroprocaine 3\% used epidurally in case of insufficient analgesia

- up-down sequential allocation method for study setup and statistical analysis of the results.

\section{Results}

- 11 patients included in the analysis

- using the isotonic regression estimator method, the ED50 $(95 \% \mathrm{Cl})$ of spinal chloroprocaine $1 \%$ was calculated to be $56(52-58) \mathrm{mg}$

- up-down sequence of doses of chloroprocaine is demonstrated in figure 1

- figure 2 shows PAVA-adjusted dose response curve.

\section{Conclusion}

- ED50 of chloroprocaine 1\% for hernia repair in outpatients is $56 \mathrm{mg}$.

- Further research is needed to determine the full-dose response curve of spinal chloroprocaine.

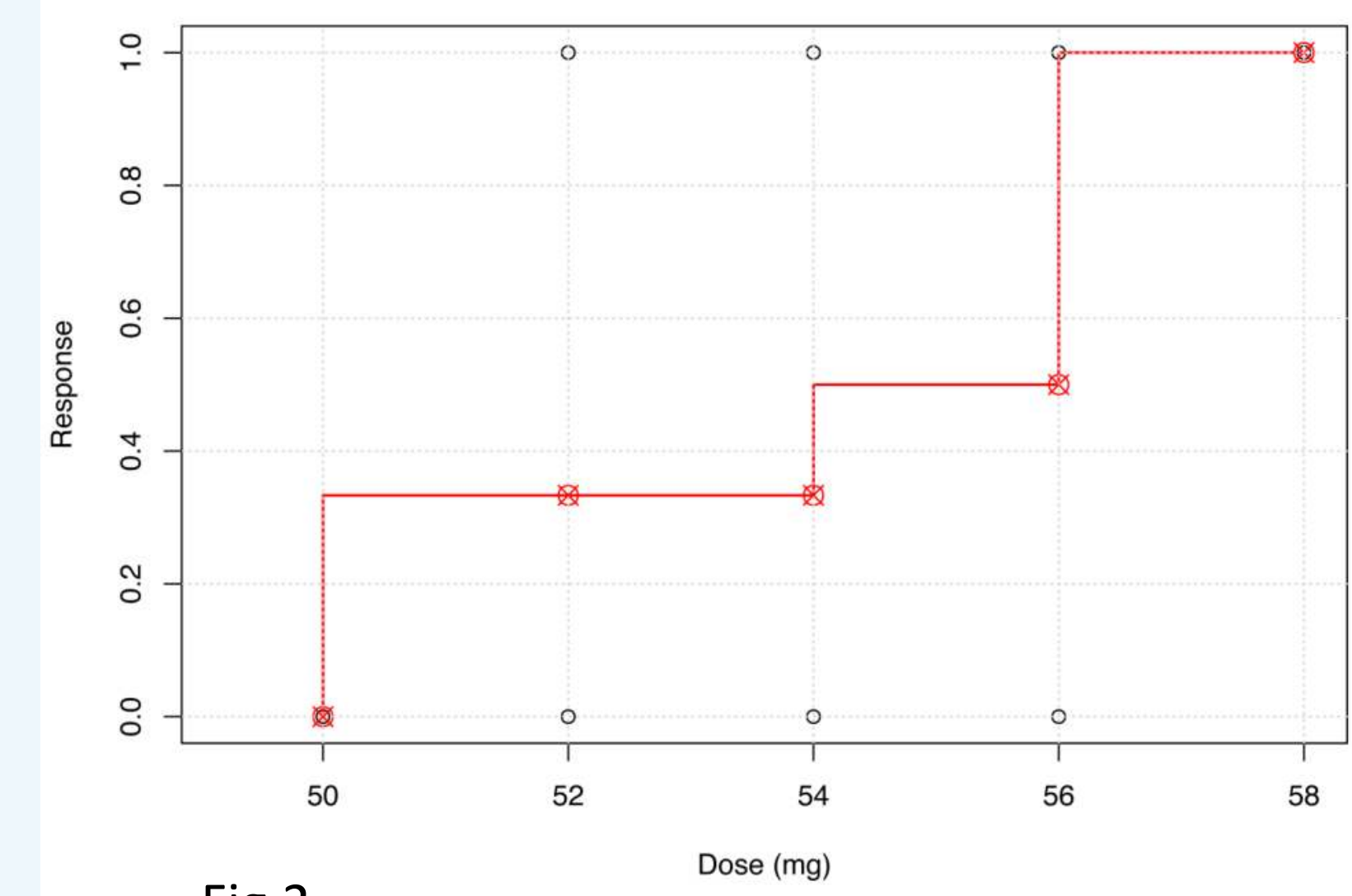

Fig.2. 